\title{
Separation and quantitation of orange juices using liquid chromatography of polymethoxylated flavones
}

\author{
P.P. Mouly ${ }^{1, *}$, E.M. Gaydou ${ }^{2}$ and C. Arzouyan ${ }^{1}$ \\ ${ }^{1}$ SGS-CERVAC (Société Générale de Surveillance-CEntre de Recherche et de VAlorisation des produits de la \\ Consommation, Parc Club des Aygalades, Bât. A7, Z.I.N. 1207, 35 Boulevard du Capitaine Gèze, \\ 13333 Marseille Cedex 14, France \\ ${ }^{2}$ Laboratoire de Phytochimie de Marseille, Faculté des Sciences et Techniques de Saint Jérôme, \\ Avenue Escadrille Normandie Niemen, 13397 Marseille Cedex 13, France
}

\begin{abstract}
A rapid method of extraction and quantitation of polymethoxylated flavones (PMF) using isocratic liquid chromatography is described. With this method the content of six PMF: sinensetin, hexamethoxyflavone, nobiletin, heptamethoxyflavone, tetra-O-methyl scutellarein and tangeretin from 60 commercial orange juices have been determined. The PMF extraction method is mainly established on sample preparations using $C_{18}$ cartridge extractions with water/acetonitrile $(60 / 40, \mathrm{v} / \mathrm{v})$ as mobile phase. PMF compositions of orange commercial juices show a quantitative difference on population samples which are linked to the PMF contents and varieties. By these rapid quantitative method, the PMF values observed were in accordance with literature. This technique present correct characteristics of repeatability and reproducibility ( $4.5 \%$ and $6.6 \%$ respectively).
\end{abstract}

Key words. Polymethoxylated flavones - extraction - determinations - liquid chromatography - orange juice.

\section{Introduction}

Various polymethoxylated flavones (PMF) which can be found in oranges, have been isolated and identified some years ago [1-3]. For example, nobiletin (NOB) and sinensetin (SIN) were isolated from sweet orange flavedo (Citrus sinensis) or, tangeretin (TAN) isolated from tangerine $(C$. reticulata) [1-3] (Fig. 1). Six PMF were isolated from orange essential oil $[4,5]$ and the PMF identified are characterized by the absence of a hydroxyl group. Their methoxylation level, heptamethoxyflavone (HEP) containing the highest methoxylation level, differentiated the PMF. The PMF are mainly located in the flavedo (external part of the citrus peel) and therefore they are found in essential oil of citrus. During the extraction process a part of the essential oil is mixed with the juice. The composition study of PMF in essential oils and in orange and mandarin juices has been largely investigated using thin layer chromatography [6], and five PMF have been identified: SIN, NOB, HEP, tetramethylscutellarein (SCU) and TAN in oranges juices and essential oils. Then, separation techniques using gas chromatography [7] and liquid chromatography (isocratic and gradient elution) have been developed [8-10], allowing a rapid and precise determination. Nevertheless, due to the low content in PMF found in mandarin and orange juices compared to the PMF content in essential oils of this citrus (from 200 to 500 fold lower in juices), many extraction techniques have been developed. One of them consist in a liquid/liquid extraction using organic solvents such as benzene or chloroform [10-12]. Another technique used for PMF extraction, the concentration on $\mathrm{C}_{18}$ cartridges after juice filtration on celite, have significantly simplified the sample preparation [9]. In this paper, we have used a rapid method of separation and quantitation of the six main PMF occurring in orange juices [SIN, hexamethoxyflavone (HEX), NOB, SCU, HEP and TAN] using an isocratic liquid chromatographic method with a $\mathrm{C}_{18}$ cartridge extraction system, to separate and quantify PMF. This method was applied for the PMF content determination in commercial orange juices and the validation of this method was achieved.

\section{Materials and methods}

\section{Samples}

The quantitative analysis of PMF content was carried out on 60 commercial orange juices composed of pure fresh juices (10 samples), pure pasteurized juices (30 samples) and juices made with concentrates (20 samples), from different varieties and origins. A ring test has been carried out on three pure valencia orange juices, 2 made from Spain (A and B) and one from Cuba (C).

\section{Standards}

Three standards (SIN, SCU and TAN), analytical grade, were obtained from Extrasynthese (Genay, France). The mother solutions of SIN, SCU and TAN were prepared at $100 \mathrm{mg} \mathrm{L}^{-1}$ in methanol (Carlo Erba) and were stable for

* Correspondence and reprints

Received December 08, 1998; revised February 12, 1999; accepted February 16, 1999. 


\section{Original articles}<smiles>COc1ccc(-c2cc(=O)c3c(OC)c(OC)c(OC)cc3o2)cc1OC</smiles>

Sinensetin : SIN<smiles>COc1ccc(-c2oc3cc(OC)c(OC)c(OC)c3c(=O)c2OC)cc1OC</smiles>

Hexamethoxyflavone: HEX<smiles>COc1ccc(-c2cc(=O)c3c(OC)c(OC)c(OC)c(OC)c3o2)cc1OC</smiles>

Nobiletin : NOB<smiles>COc1ccc(-c2oc3c(C)c(OC)c(OC)c(OC)c3c(=O)c2OC)cc1OC</smiles>

Heptamethoxyflavone : HEP<smiles>COc1ccc(-c2cc(=O)c3c(OC)c(OC)c(OC)cc3o2)cc1</smiles>

Tetramethyl-O-scutellarein : SCU<smiles>COc1ccc(-c2cc(=O)c3c(OC)c(OC)c(OC)c(OC)c3o2)cc1</smiles>

Tangeretin : TAN

Fig. 1. Chemical structure of polymethoxylated flavones.

10 weeks at $-18{ }^{\circ} \mathrm{C}$. The final standard solution (prepared before each quantification) was obtained by dilution with methanol of the main solution in a $100 \mathrm{~mL}$ volumetric flask to obtain a concentration at $25 \mathrm{mg} \mathrm{L}^{-1}$ for SIN, at $20 \mathrm{mg} \mathrm{L}^{-1}$ for SCU and at $10 \mathrm{mg} \mathrm{L}^{-1}$ for TAN.

\section{Solvents}

The solvents used were of HPLC grade (Carlo Erba). The purification solvent (PS) was a water/acetonitrile mixture $(72 / 28, v / v)$ and the extraction solvent (ES) a methanol/chloroform mixture $(50 / 50, \mathrm{v} / \mathrm{v})$.

\section{Sample preparations}

The time indicated in brackets must be observed to obtain good reproducibility and repeatability on results during the various steps of sample preparations. Orange juice $(50 \mathrm{~mL})$ was centrifugated at $2500 \mathrm{rpm}$ during $10 \mathrm{~min}$.

Sample clean-up: the reversed phase cartridge $\left(\mathrm{C}_{18}\right.$ cartridges, Sep-Pack, Waters, France) was conditioned using respectively $5 \mathrm{~mL}$ of acetonitrile $(15 \mathrm{~s})$ and $2 \times 5 \mathrm{~mL}$ of water $(15 \times 2 \mathrm{~s})$ (HPLC grade, BdH, France). Then the clarified sample $(10 \mathrm{~mL})$ is filtered through the cartridge $(1 \mathrm{~min})$ and the eluate is discarded. The cartridge is washed with $5 \mathrm{~mL}$ of water $(15 \mathrm{~s})$ and then, with $5 \mathrm{~mL}$ of PS to eliminate other polyphenolic compounds beside PMF and remaining on the cartridge. The cartridge is dried with a flow of nitrogen (4.9 purity, Linde, France). The PMF were extracted from the cartridge with $5 \mathrm{~mL}$ of ES (15 s) and the solvent layer evaporated to dryness under vacuum $\left(35^{\circ} \mathrm{C}\right)$. The PMF were dissolved in $1 \mathrm{~mL}$ of methanol with an automatic syringe before injection.

\section{Liquid chromatography}

All solvents used were of HPLC grade, the separation can be achieved using $\mathrm{C}_{18}$ columns, such as those used for this study: Kromasil, Touzart et Matignon, $150 \times 4.6 \mathrm{~mm}$ i. d., $5 \mu \mathrm{m}$; Waters, Spherisorb ODS2 $250 \times 4.6 \mathrm{~mm}$ i.d., $5 \mu \mathrm{m}$; Alltech, Alltima $250 \times 4.6 \mathrm{~mm}$ i.d., $5 \mu \mathrm{m}$; Life International et Hypersil ODS $250 \times 4.6 \mathrm{~mm}$ i.d., $5 \mu \mathrm{m}$. A Waters 600 controller pump was used for analyses and a Waters 996 photodiode array detector (PAD) was set at $330 \mathrm{~nm}$. The samples were introduced onto the column via an automatic injector (Waters 717) equipped with a sample loop $(20 \mu \mathrm{L})$. The PMF were eluted with a mobile phase composed of a water/acetonitrile mixture (60/40, v/v), chromatographic data were handled with a Millenium driver station, the column was set at ambient temperature (constant between 20 and $25{ }^{\circ} \mathrm{C}$ ) and the flow rate was fixed at $1.0 \mathrm{~mL} \mathrm{~min}{ }^{-1}$. The $\mathrm{PMF}$ contained in orange juices were identified by comparison of their retention times and UV spectra with literature and with those of standards for SIN, SCU and TAN.

\section{Polymethoxylated flavone determination results}

The PMF contents were expressed in percentage of total peaks taken in account [9] and in $\mathrm{mg} \mathrm{L}^{-1}$. Concentration in $\mathrm{mg} \mathrm{L}^{-1}$ for SIN, SCU and TAN were determined by 


\section{Original articles}

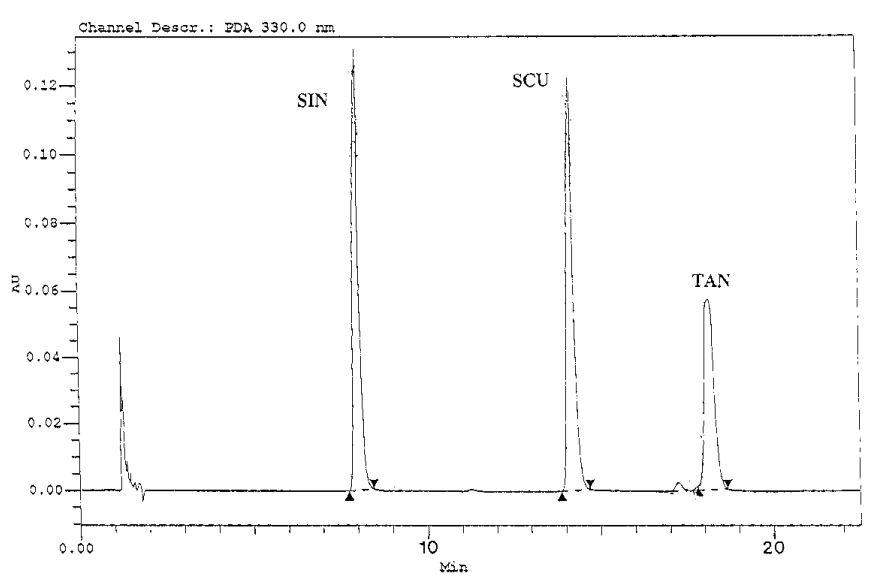

Fig. 2. Liquid chromatographic separations of polymethoxylated flavone standards. Column $\mathrm{C}_{18}(150 \times 4.6 \mathrm{~mm}$ i.d. $)$; amount injected $20 \mu \mathrm{L}$ of a solution at $25 \mathrm{mg} \mathrm{L}^{-1}$ for SIN, $20 \mathrm{mg} \mathrm{L}^{-1}$ for $\mathrm{SCU}$ and $10 \mathrm{mg} \mathrm{L}^{-1}$ for TAN. For identification of compounds see figure 1 .

external calibration method using response factor of standards. Concentration in $\mathrm{mg} \mathrm{L}^{-1}$ of HEX, NOB and HEP was expressed as the mean response factor standard peaks of SIN, SCU and TAN.

\section{Results and discussion}

Figure 2 shows the elution of standards in our chromatographic conditions and figure 3 shows the PMF profile which characterise orange juices extracted on $\mathrm{C}_{18}$ cartridges. The same elution order with comparable retention times is observed with an ODS column (Hypersil $250 \times 4.6 \mathrm{~mm}$, i.d., $5 \mu \mathrm{m})$. Figure 3 shows a high content in SIN and NOB, a relative low content in HEX, SCU and HEP and a low content in TAN. These results are in agreement with precedent studies on PMF orange juice contents [9-12].

The PMF results (Tab. I) have been obtained on 60 commercially orange juices. We can observe a large range of PMF contents (expressed in $\mathrm{mg} \mathrm{L}^{-1}$ ) from 1.88 to $7.54 \mathrm{mg}$ $\mathrm{L}^{-1}$ with a mean coefficient of variation at $43.3 \%$. These variations are mainly linked with the essential oil contained

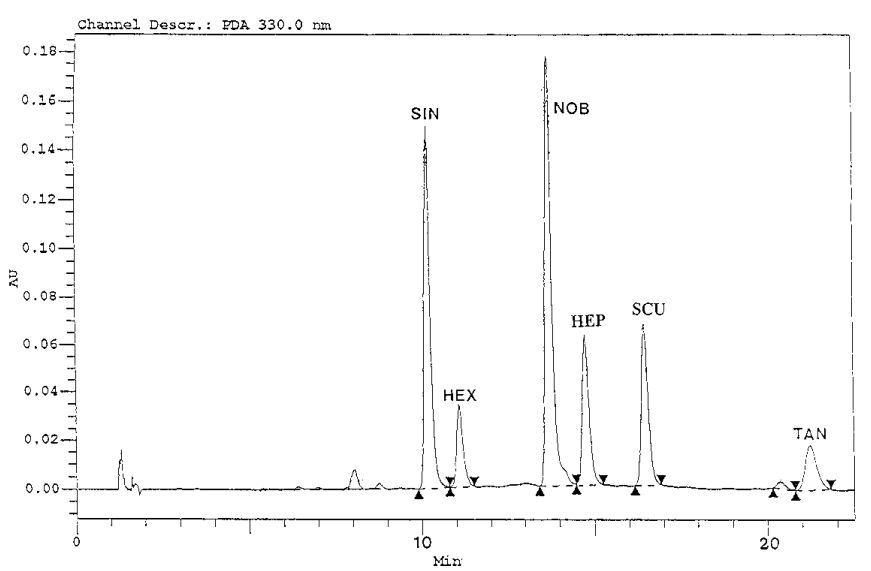

Fig. 3. Liquid chromatography of orange juice polymethoxylated flavones. For extraction and chromatographic conditions see experimental section. For identification of compounds see figure 1.

in juices and the varieties investigated. The PMF are occurring from the essential oil located in the citrus pericarp [13]. PMF Content in orange juice depends of pressing level and the kind extraction process used. Sendra et al. [9] have shown that the PMF contents are 10 to 40 fold lower in handly pressing juices (mean of $0.33 \mathrm{mg} \mathrm{L}^{-1}$ ) versus 2.8 to $10.8 \mathrm{mg} \mathrm{L}^{-1}$ in industrial orange juices.

Variation of PMF contents is mainly explained by the variety effect which can be shown by results expressed in relative percentage, since they are independent of the essential oil added. Therefore the relative coefficient of variation on the 60 samples is less important (mean, 6.1\%). An important variation on the relative coefficient of variation percentage of TAN is observed $(52.4 \%)$. The expression of results in relative percentage caused a lost of part of information such as the essential oil content in orange juices directly linked at the PMF content. This kind of information are present in results expressed in $\mathrm{mg} \mathrm{L}^{-1}$.

Table II shows the mean of results expressed in percentage of total peaks taken in account and in $\mathrm{mg} \mathrm{L}^{-1}$ of PMF for the 60 commercial orange juices. These results in

Table I. Polymethoxylated flavone content in commercial orange juices.

\begin{tabular}{|c|c|c|c|c|c|c|c|c|}
\hline & \multirow[b]{2}{*}{ Min-Max } & \multicolumn{3}{|c|}{ Results in $m g L^{-1 a}$} & \multicolumn{4}{|c|}{ Results in $\%^{a}$} \\
\hline & & Mean & $S D^{b}$ & $C V \%^{c}$ & Min-Max & Mean & $S D^{b}$ & $C V \%^{c}$ \\
\hline SIN & $0.56-1.99$ & 1.12 & 0.42 & 37.5 & $26.3-29.8$ & 27.2 & 1.7 & 6.3 \\
\hline HEX & $0.13-0.45$ & 0.27 & 0.13 & 48.1 & $6.0-6.9$ & 6.6 & 0.4 & 6.1 \\
\hline NOB & $0.61-2.65$ & 1.38 & 0.51 & 37.0 & $32.4-35.1$ & 33.6 & 1.4 & 4.2 \\
\hline HEP & $0.24-0.85$ & 0.50 & 0.20 & 40.0 & $11.3-12.8$ & 12.2 & 0.8 & 6.6 \\
\hline SCU & $0.27-1.03$ & 0.58 & 0.25 & 43.1 & $13.7-14.4$ & 14.1 & 0.3 & 7.3 \\
\hline TAN & $0.07-0.57$ & 0.26 & 0.14 & 53.8 & $3.7-7.6$ & 6.3 & 3.3 & 52.4 \\
\hline
\end{tabular}

a: Values obtained with 60 commercially orange juices; b: standard deviation; c: coefficient of variation. 
Table II. Polymethoxylated flavone contents obtained in orange juices compared to literature values.

\begin{tabular}{|c|c|c|c|c|c|}
\hline \multirow[t]{2}{*}{$P M F$} & \multicolumn{2}{|c|}{ Exp. in area \% } & \multicolumn{3}{|c|}{ Exp. in $m g L^{-1}$} \\
\hline & $\begin{array}{c}\text { Our work } \\
\text { Mean }\end{array}$ & $\begin{array}{c}{[10]^{b}} \\
\text { Area \% }\end{array}$ & $\begin{array}{c}\text { Our } \text { work }^{a} \\
\text { Mean }\end{array}$ & $\begin{array}{c}{[9]^{b}} \\
m g L^{-1}\end{array}$ & $\begin{array}{c}{[11]^{b}} \\
m g L^{-1}\end{array}$ \\
\hline SIN & 27.2 & 26.8 & 1.12 & $0.81-2.94$ & 0.73 \\
\hline HEX & 6.6 & 6.1 & 0.27 & - & - \\
\hline NOB & 33.6 & 34.5 & 1.38 & $1.09-4.31$ & 1.00 \\
\hline HEP & 12.2 & 12.5 & 0.50 & $0.52-1.87$ & 0.57 \\
\hline SCU & 14.1 & 12.0 & 0.58 & $0.26-1.10$ & 0.27 \\
\hline TAN & 6.3 & 6.7 & 0.26 & $0.14-0.61$ & 0.13 \\
\hline
\end{tabular}

a: Values obtained with 60 juices; b: reference number.

Table III. Reproducibility obtained in a ring test of the polymethoxylated flavone determination with three pure orange juicesa.

\begin{tabular}{|c|c|c|c|c|c|c|c|c|}
\hline \multirow[b]{2}{*}{ JUICE } & \multicolumn{4}{|c|}{ Results in $m g L^{-1}$} & $\begin{array}{c}\text { Resul } \\
\text { Mean }\end{array}$ & $\begin{array}{l}\text { lts in } \\
S_{R-1}\end{array}$ & $\begin{array}{l}\text { relative } \\
\left(R S D_{R}\right) \%\end{array}$ & $\begin{array}{l}\%^{\mathrm{f}} \\
\% R\end{array}$ \\
\hline & & & & & & & & \\
\hline SIN & 0.79 & 0.08 & 10.0 & 0.19 & 28.2 & 1.5 & 5.4 & 4.2 \\
\hline HEX & 0.18 & 0.02 & 11.1 & 0.06 & 7.1 & 0.5 & 7.1 & 1.4 \\
\hline NOB & 0.86 & 0.07 & 7.6 & 0.17 & 32.6 & 1.3 & 4.0 & 3.6 \\
\hline HEP & 0.38 & 0.03 & 6.8 & 0.15 & 14.0 & 0.5 & 3.6 & 1.4 \\
\hline SCU & 0.39 & 0.07 & 17.9 & 0.07 & 14.3 & 0.5 & 3.6 & 1.4 \\
\hline TAN & 0.15 & 0.01 & 7.7 & 0.03 & 5.0 & 0.6 & 10 & 1.6 \\
\hline \multicolumn{9}{|c|}{ JUICE B } \\
\hline SIN & 0.67 & 0.03 & 3.8 & 0.07 & 29.3 & 1.0 & 3.3 & 2.7 \\
\hline HEX & 0.13 & 0.03 & 24.3 & 0.09 & 5.3 & 0.5 & 9.4 & 1.4 \\
\hline NOB & 0.73 & 0.02 & 2.8 & 0.06 & 35.3 & 2.2 & 6.3 & 6.2 \\
\hline HEP & 0.24 & 0.02 & 8.7 & 0.06 & 11.8 & 0.5 & 4.3 & 1.4 \\
\hline SCU & 0.24 & 0.05 & 20.6 & 0.14 & 12.5 & 1.7 & 13.9 & 4.8 \\
\hline TAN & 0.12 & 0.02 & 17.5 & 0.06 & 5.0 & 0 & 0 & 0 \\
\hline \multicolumn{9}{|c|}{ JUICE C } \\
\hline SIN & 0.9 & 0.07 & 7.3 & 0.19 & 28.4 & 2.3 & 8.1 & 6.4 \\
\hline HEX & 0.16 & 0.02 & 9.4 & 0.04 & 5.8 & 1.0 & 16.5 & 2.7 \\
\hline NOB & 1.07 & 0.07 & 6.8 & 0.21 & 35.8 & 2.3 & 6.4 & 6.4 \\
\hline HEP & 0.35 & 0.02 & 5.4 & 0.05 & 11.8 & 0.5 & 4.2 & 1.4 \\
\hline SCU & 0.36 & 0.03 & 8.0 & 0.08 & 12.8 & 0.5 & 3.9 & 1.4 \\
\hline TAN & 0.17 & 0.01 & 6.4 & 0.03 & 5.3 & 0.5 & 9.4 & 1.4 \\
\hline
\end{tabular}

a: According to NF ISO 5725 norm [14]; b: mean of 5 laboratories; c: reproducibility standard deviation; d: reproducibility relative standard deviation; e: reproducibility limit; $\mathrm{f}$ : expressed in \% of total peaks taken in account.

agreement with literature, show that the simplification of sample preparations and chromatographic conditions have no influence on quantitative results.
Repeatability relative standard deviation $\left(\mathrm{RSD}_{\mathrm{r}}\right)$ realized on six samples, each in triplicate have given the following results: SIN: 1.9\%; HEX; 2.5\%; NOB: $2.6 \%$; SCU: $1.9 \%$; HEP: $4.1 \%$ and TAN: $3.8 \%$ (results expressed in $\mathrm{mg} \mathrm{L}^{-1}$ ). The recovery realized on four orange juices each in triplicate have been done on results expressed in $\mathrm{mg} \mathrm{L}^{-1}$ with SIN (97\%), SCU (95\%) and TAN (97\%). Table III gives the reproducibility of the method (in accordance with NF ISO 5725 norm, [14]). The method reproducibility has been done with three samples of pure orange juices $(\mathrm{A}, \mathrm{B}, \mathrm{C})$ by five laboratories. The results have been expressed in $\mathrm{mg} \mathrm{L}^{-1}$ and in relative percentage. In this table we can remark a large dispersion on the results expressed in $\mathrm{mg} \mathrm{L}^{-1}$ principally on HEX, SCU and TAN who present a relative standard deviation of reproducibility $\left(\mathrm{RSD}_{\mathrm{R}}\right)$ important $(14.9 \%, 15.5 \%$ and $10.5 \%$ respectively). The other PMF present a correct $\mathrm{RSD}_{\mathrm{R}}$ (SIN: $7.0 \%$; NOB: $5.7 \%$ and HEP: $7.0 \%$ ). If we compare $\mathrm{RSD}_{\mathrm{R}}$ with results expressed in $\mathrm{mg} \mathrm{L}^{-1}$ and $\mathrm{RSD}_{\mathrm{R}}$ with results expressed in relative percentage, a better reproducibility on all PMF is observed. A good reproducibility within laboratories during the ring test is observed with all PMF, taking into account that the errors during sample preparations, using results expressed in relative percentage, are lowered since they don't take in account the possible lost of PMF.

\section{Conclusion}

Quantitative analyses of six PMF have shown a large dispersion of PMF contents on 60 commercial orange juices elaborated from three kind industrial processes (pure fresh juices, pure pasteurized juices and juices made from concentrate). Nevertheless, the results obtained are in agreement with those obtained in other preparation conditions of samples and/or other chromatographic conditions. The convenience to use many kind of $\mathrm{C}_{18}$ column (4 kind of columns have been tested in this study) contributes to the robustness of this rapid quantitation method. This method gives a correct relative standard deviation of repeatability $\left(\mathrm{RSD}_{\mathrm{r}}: 4.5 \%\right.$ in mean), a good recovery ( $94 \%$ in mean) and a correct relative standard deviation of reproducibility on the results expressed in percentage of total peak taken into account $\left(\mathrm{RSD}_{\mathrm{R}}: 6.6 \%\right.$ in mean).

\section{Acknowledgements}

This collaborative study have been realized in the case of A.I.R. 2 program (Agro Industry Research) - CT 94 - 1111, coordinate work realized by J.-P. Richard (A.B.C. society, Paris, France) and UNPJF (Union Nationale des Producteurs de Jus de Fruits, Paris, France). The authors thank the following participants: J. Llorca (Joker society, Macon, France), M.-H. Salagoïty (DGCCRF, Bordeaux, France), W. Ooghe (University of Gent, Belgium) for their contribution, E. Truchot, M. Guavard (Lara society, Toulouse, France) and G. Fuchs, H.-J. Hofsommer (GFL, Berlin, Germany) for their participation during the ring test and L. 


\section{Original articles}

Lapierre (Couecou society, Biarritz, France) for the gift of authentic orange juices.

\section{References}

1. Kefford, J. B.; Chandler, B. V. The chemical constituent of Citrus fruits; Academic: New York, 1970; pp 113-148.

2. Ting, S. V.; Attaway, J. A. In: The biochemistry of fruits and their products; Academic Press: London, 1971, pp 107-171.

3. Verkatamaran, K. In The flavonoids; Harborne, J. B.; Mabry, H., Eds.; Chapman \& Hall: London, 1975; pp 267-295.

4. Gaydou, E. M.; Bianchini, J. P.; Ramananarivo, S. B. Bull. Liaison Groupe Polyphénols 1984, 12, 129-130.

5. Gaydou, E. M.; Bianchini, J. P.; Randriamiharisoa, R. P. J. Agric. Food Chem. 1987, 35, 525- 529.

6. Veldhuis, M. K. In: Fruit and vegetable juice processing technology; Tressler, D. K.; Joslyn, M. A. Eds.; AVI Publishing Company: Wesport, USA, 1971; pp 31-91.
7. Gaydou, E. M.; Berahia, T.; Wallet, J. C.; Bianchini, P. J. Chromatogr. 1991, 549, 440-445.

8. Heimhuber, B.; Galensa, R.; Herrman, K. Chromatogr. 1988, 439, 481- 483.

9. Sendra, J. M.; Navarro, J. L.; Izquierdo, L. Chromatogr. Sci. 1988, 26, 443-445.

10. Ooghe, W. C.; Ooghe, S. J.; Detavernier, C. M.; Huyghebaert, A. J. Agric. Food Chem. 1994, 42, 2191-2195.

11. Rouseff, R. L.; Ting, S. V. J. Chromatogr. 1979, 176, 75-87.

12. Ting, S. V.; Ting, R. L.; Dougherty, M. H.; Attaway, J. A. J. Food Sci. 1979, 44, 69-71.

13. Allbrigo, G. L.; Carter, R. D. In: Citrus science and technology; Nagy, S.; Vol. 1; Shaw, P. E.; Veldhuis, M. K., Eds.; The Avi Publishing Company: Wesport, Connecticut, 1977; pp 33-73.

14. NF ISO 5725, In: Basic method for the determination of reapeatability and reproducibility of a standard measurement method, AFNOR, Association Française de NORmalisation, Paris, France, Part 2. 